\title{
Gyrification, cortical and subcortical morphometry in neurofibromatosis type 1: an uneven profile of developmental abnormalities
}

\author{
Inês R Violante ${ }^{1}$, Maria J Ribeiro ${ }^{1}$, Eduardo D Silva² ${ }^{2}$ and Miguel Castelo-Branco ${ }^{1 *}$
}

\begin{abstract}
Background: Neurofibromatosis type 1 (NF1) is a monogenic disorder associated with cognitive impairments. In order to understand how mutations in the NF1 gene impact brain structure it is essential to characterize in detail the brain structural abnormalities in patients with NF1. Previous studies have reported contradictory findings and have focused only on volumetric measurements. Here, we investigated the volumes of subcortical structures and the composite dimensions of the cortex through analysis of cortical volume, cortical thickness, cortical surface area and gyrification.

Methods: We studied 14 children with NF1 and 14 typically developing children matched for age, gender, IQ and right/left-handedness. Regional subcortical volumes and cortical gyral measurements were obtained using the FreeSurfer software. Between-group differences were evaluated while controlling for the increase in total intracranial volume observed in NF1.

Results: Subcortical analysis revealed disproportionately larger thalami, right caudate and middle corpus callosum in patients with NF1. Cortical analyses on volume, thickness and surface area were however not indicative of significant alterations in patients. Interestingly, patients with NF1 had significantly lower gyrification indices than typically developing children primarily in the frontal and temporal lobes, but also affecting the insula, cingulate cortex, parietal and occipital regions.

Conclusions: The neuroanatomic abnormalities observed were localized to specific brain regions, indicating that particular areas might constitute selective targets for NF1 gene mutations. Furthermore, the lower gyrification indices were accompanied by a disproportionate increase in brain size without the corresponding increase in folding in patients with NF1. Taken together these findings suggest that specific neurodevelopmental processes, such as gyrification, are more vulnerable to NF1 dysfunction than others. The identified changes in brain organization are consistent with the patterns of cognitive dysfunction in the NF1 phenotype.
\end{abstract}

Keywords: Brain structure, Gyrification, Morphometry, MRI, Neurodevelopmental disorders, Neurofibromatosis type 1

\footnotetext{
* Correspondence: mcbranco@fmed.uc.pt

'Institute for Biomedical Imaging and Life Sciences, Faculty of Medicine, University of Coimbra, Azinhaga de Santa Comba, Coimbra 3000-548, Portugal

Full list of author information is available at the end of the article
} 


\section{Background}

Brain development is dependent on a series of complex events including cellular proliferation, growth, differentiation and migration, programmed cell death and synaptic elimination. These events largely determine brain morphology [1]. Since brain structure is under significant genetic influence [2] it is important to use genetic models to understand its ontogeny.

Neurofibromatosis type 1 (NF1) is a good model in this respect, because it is a monogenic disorder caused by mutations in the NF1 gene. The disorder has a prevalence of 1 in 3,500 [3] and is characterized by alterations in skin pigmentation (café-au-lait spots and skinfold freckling), increased tumor predisposition and learning deficits $[4,5]$. In the brain, neurofibromin, the protein product of the NF1 gene, is expressed in both neurons and glial cells [6,7] and is required for neural development $[8,9]$. Loss of neurofibromin results in increased cellular growth [10], while it is also involved in learning and memory [11]. Thus, this disease provides a unique window into gene-brain-behavior relationships. The role of neurofibromin in cellular growth and its ubiquitous expression in the brain suggest that brain structure might be affected in patients. In fact, there is a high incidence of macrocephaly, optic gliomas and T2-weighted hyperintensities, commonly referred to as unidentified bright objects (UBOs) [12]. Nevertheless, the gross brain anatomy appears normal and it has been difficult to determine if brain structure is altered independent of focal lesions.

Recent advances in neuroimaging allow for an increasingly detailed delineation of developmental anomalies. Previous studies focusing on NF1 brain structure have examined the relative contributions of gray matter (GM) and white matter (WM) to increased brain size, with contradictory results [12]. The majority of studies point to macrocephaly being caused by increased WM $[13,14]$ or a combination of WM and GM $[15,16]$. Only one study pointed to an increase in GM [17]. However, few reports attempted to identify regional abnormalities. Cutting et al. [15] focused on frontal and parietal lobe subdivisions and found they presented increased WM volume. Greenwood et al. [16] divided the brain into 16 parcellations and, besides a total increase in GM and WM volumes in patients with NF1, they reported increased GM in occipital and parietal regions and increased WM in anterior regions. Other brain structure anomalies observed included increased brainstem growth rate, suggestive of abnormal cell proliferation [18], smaller surface area and GM volume of the left planum temporale of NF1 boys compared with controls [19] and abnormal thalamic metabolic patterns observed with positron emission tomography [20] and magnetic resonance spectroscopy [21]. Furthermore, in a previous study from our laboratory, support vector machines were able to reveal the existence of brain structural differences in GM and WM tissue that could accurately discriminate individuals with NF1 from controls [22].

However, no previous study performed morphometric measurements of subcortical and cortical structures across the whole brain. Moreover, we extended our investigation beyond the volumetric dimension as alterations in neurofibromin expression might be differently reflected across the brain and manifest in distinct structures and morphological traits.

In this study, our aim was to provide a multidimensional morphometric analysis to clarify how brain structure is affected by NF1; to do this, we measured subcortical and cortical volumes, cortical thickness, cortical surface area and gyrification across the entire brain. The importance of assessing multiple morphometric traits is explained by the fact that they underlie distinctive evolutionary [23], developmental $[24,25]$ and possible genetic [26] processes. A crucial point in our study was a careful matching of the control group, as several factors are known to influence brain morphology, including age [25], gender [27], intelligence [28,29] and handedness [30]. A number of previous studies focusing on structural alterations in NF1 were biased by gender [15] or included patients with brain tumors [16,17]. Moreover, the majority of studies lacked matching for intelligence quotient (IQ). In contrast, in the present study, patient and control groups did not show significant differences in age, gender, handedness or IQ.

The present multidimensional whole brain study is of an exploratory nature. However, given the previous reported imaging findings, the range of neuropsychological deficits observed in patients and the wide expression of neurofibromin in the brain we hypothesized that the pattern of alterations would not be limited to one brain region. Moreover, based on previous neuroimaging studies $[15,16]$, we expected that the alterations observed will include frontal and parietal neocortical regions and at the subcortical level the corpus callosum [14,22,31-34].

\section{Methods}

\section{Ethics statement}

The study was conducted in accordance with the Declaration of Helsinki and all procedures were reviewed and approved by the Ethics Commissions of the Faculty of Medicine of the University of Coimbra and of the Children's Hospital of Coimbra. Written informed consent was obtained from the parents/guardians of all participants. Children and adolescents gave written or oral informed consent.

\section{Subjects}

The participants in this study belong to a larger cohort from our previous studies [22,35] and were selected so 
that the groups were matched for age, gender, IQ and handedness. We studied 14 patients with NF1 (mean age: $11.34 \pm 2.51 \mathrm{SD}$; age range: 7.83 to 16.08 years; 6 males, 8 females) and 14 matched typically developing (TD) subjects (mean age: $11.89 \pm 2.06 \mathrm{SD}$; age range: 7.83 to 15.33 years; 5 males, 9 females). All participants were right-handed.

Patients were recruited and diagnosed in collaboration with the Clinical Genetics Department of the Pediatric Hospital of Coimbra according to the NIH defined diagnostic criteria [36]. The TD group was recruited from a local school. Exclusion criteria for all participants were as follows: psychiatric disorder, neurological illness affecting brain function other than NF1, epilepsy, tumors or other clinically significant intracranial abnormality detected on magnetic resonance imaging (MRI). UBOs, areas of increased $\mathrm{T}_{2}$-weighted signal intensity on MRI with unknown etiology, commonly found in patients with NF1, were not considered exclusion criteria when present in patients. Additionally, we only included patients with intelligence quotient $\geq 90$ in order to be able to match to typically developing children. On average, IQs reported in children with NF1 tend to be lower, with mean values around 90 (as reviewed by Ozonoff et al. [37]). Children prescribed with stimulant medication (methylphenidate) were not medicated on the day of MRI acquisition and neuropsychological assessment (3 NF1).

Neuropsychological assessment was performed using the Portuguese adapted version of the Wechsler Intelligence Scale for Children III (WISC-III) [38]. The demographic and neuropsychological characterization of both groups is shown in Table 1.

\section{MRI acquisition}

Scanning was performed on a 3T Siemens TimTrio scanner, using a 12-channel birdcage head coil. In this study we analyzed acquired data with the following parameters: (i) two $\mathrm{T}_{1}$-weighted $\left(\mathrm{T}_{1} \mathrm{w}\right)$ magnetization-prepared rapid acquisition with gradient echo (MPRAGE) sequences, $1 \times$ $1 \times 1 \mathrm{~mm}$ voxel size, repetition time (TR) $2.3 \mathrm{~s}$, echo time (TE) $2.98 \mathrm{~ms}$, flip angle (FA) $9^{\circ}$, field of view (FOV) $256 \times$
256, 160 slices; (ii) a $\mathrm{T}_{2}$-weighted $\left(\mathrm{T}_{2} \mathrm{w}\right)$ fluid attenuated inversion recovery (FLAIR) sequence, $1 \times 1 \times 1 \mathrm{~mm}$ voxel size, TR 5 s, TE 2.98 ms, Inversion Time (TI) 1.8 s, FOV $250 \times 250,160$ slices. FLAIR images were used to identify $\mathrm{T}_{2}$ hyperintensities. A neuroradiologist blinded to the participants' clinical history observed the magnetic resonance structural scans and reported on the distribution and number of UBOs.

\section{MRI data analyses}

Cortical reconstruction and volumetric segmentation were performed with the FreeSurfer image analysis suite (FreeSurfer v5.1.0, http://surfer.nmr.mgh.harvard.edu), as described in previous publications [39-41]. Briefly the processing included, motion correction, averaging of the two $\mathrm{T}_{1} \mathrm{w}$ images, registration to Talairach space, segmentation of the subcortical WM and deep GM volumetric structures $[41,42]$, intensity normalization, tessellation of the GM/WM boundary, automated topology correction $[43,44]$, and surface deformation following intensity gradients to optimally place the GM/WM and GM/cerebrospinal fluid (CSF) borders [39]. Image outputs were visually inspected and inaccuracies corrected when required. FreeSurfer provided correct segmentation and classification of subcortical structures in spite of the presence of UBOs in patients with NF1. UBOs were included as belonging to the structure they appeared on, as demonstrated in Additional file 1: Figure S1. Registration was performed to a spherical atlas [45]. Cortical thickness was calculated by computing the average shortest distance between the GM/WM and the GM/CSF surface [40]. Surface area maps of the GM/WM boundary were computed for each subject by calculating the area of every triangle in a cortical surface tessellation, as implemented in FreeSurfer. In anatomical regions of interest, surface area values were calculated by summing the triangular area tessellations included in the region. Local gyrification indices (LGIs) were computed using local measurements of gyrification over the whole cortical surface using the method developed by Schaer et al. [46]. The LGI reflects at each vertex the amount of cortical surface area than can be packed under a sphere with a fixed size.

Table 1 Demographic and neuropsychological characterization

\begin{tabular}{|c|c|c|}
\hline & NF1 $(n=14)$ & TD $(n=14)$ \\
\hline Age & $11.34(2.51)$, range: 7.83 to 16.08 & 11.89 (2.06), range: 7.83 to 15.33 \\
\hline Gender (M:F) & $6 \mathrm{M}: 8 \mathrm{~F}$ & $5 \mathrm{M}: 9 \mathrm{~F}$ \\
\hline Handedness (right:left) & $14: 0$ & $14: 0$ \\
\hline FSIQ & 104.36 (13.41), range: 90 to 126 & 110.00 (10.97), range: 90 to 124 \\
\hline VIQ & 107.28 (11.38), range: 94 to 126 & 109.86 (11.90), range: 93 to 129 \\
\hline $\mathrm{PIQ}$ & 99.43 (12.43), range: 80 to 119 & 109.07 (12.86), range: 87 to 136 \\
\hline
\end{tabular}

Data are mean (SD).

NF1 = neurofibromatosis type $1 ; \mathrm{TD}=$ typically developing; FSIQ = full-scale intelligence quotient; $\mathrm{VIQ}=$ verbal intelligence quotient;PIQ = performance intelligence quotient. 
Cortical volume, surface area, cortical thickness and the LGIs were estimated for 34 gyral regions per hemisphere by determining the mean values of each of these variables belonging to a gyral region of interest, as defined by the atlas developed by Desikan et al. [47], recently modified to include the insula as a region of interest. GM volume was estimated for subcortical structures. WM and GM brain volumes, WM and GM cerebellar volumes, WM and GM lobar volumes and total intracranial volumes (TIV) were also estimated for each participant. TIV was calculated using a validated method shown to be proportional to manually measured total intracranial volume [48]. Briefly, an atlas scaling factor is determined based on the transformation matrix of the atlas normalization for each individual subject. The atlas scaling factor is then used to scale the intracranial volume of the atlas to compute each subject TIV. Lobar metrics were extracted using FreeSurfer's built-in lobe surface maps. The GM parcellation is based on the regions defined by the Desikan atlas [47] and the WM parcellation is performed as described in Salat et al. [49].

\section{Statistical analyses}

Statistical analyses were performed with PAWS Statistics 18 (SPSS Inc., Chicago, IL, USA). First, we verified the normality assumption for the different parameters using the Shapiro-Wilk test. All data were normally distributed. Group differences in demographic and neuropsychological data were evaluated with independent samples t test, while a $\chi^{2}$ test was used for gender. Whole-brain volumetric analysis including overall GM and WM volumes, were assessed using independent samples t tests and also using analysis of covariance (ANCOVA) to control for TIV. Lobar and cerebellar WM and GM group differences were investigated using repeated measures ANCOVA with group (NF1 vs TD) as the between-subjects factor and hemispheres (left vs right) and brain regions (lobes/cerebellar WM/cerebellar GM) as the within-subjects factors and total intracranial volume (TIV) as covariate. Analyses of subcortical volumetric differences were assessed using multivariate ANCOVA with TIV as covariate. Cortical differences between groups were investigated using repeated measures ANCOVA with group (NF1 vs TD) as the between-subjects factor and hemispheres (left vs right) and brain regions (34 gyral regions) as the within-subjects factors and TIV as covariate. Follow-up tests were performed using multivariate ANCOVAs with TIV as covariate. Relationships between brain measurements and age were studied using Pearson's correlations.

To control for type I errors we used the Benjamini and Hochberg [50] false discovery rate (FDR) method, which was applied per analysis. We set $q=0.05$ or 0.1 (that is, $5 \%$ or $10 \%$ false positives). Multiple ROI-based analyses survived FDR control at $q=0.1$ and several survived FDR control at $q=0.05$. Although FDR at $q=0.1$ can be considered a liberal correction for multiple comparisons, the exploratory nature of the present study should be taken into account.

\section{Results}

\section{Demographic and neuropsychological}

Demographic and neuropsychological data are described in Table 1. Children with NF1 and typically developing (TD) children did not differ significantly in age $\left(\mathrm{t}_{(26)}=\right.$ $-0.632, P=0.533)$, IQ $\left(\mathrm{t}_{(26)}=-1.219, P=0.234\right)$, verbal IQ $\left(\mathrm{t}_{(26)}=-0.584, P=0.564\right)$, or gender $\left(\chi^{2}=0.150, P=\right.$ $0.699)$. Performance IQ was marginally significant $\left(\mathrm{t}_{(26)}=\right.$ $-2.016, P=0.054)$, with larger scores observed in TD children.

One or more UBOs were present in $85.7 \%$ (12 out of 14 ) of the children with NF1 distributed as follows: $85.7 \%$ ( $\mathrm{n}=12$ ) of the patients had UBOs in the globus pallidus, $21.4 \%(n=3)$ in the thalami, $14.3 \%(n=2)$ in the corpus callosum, $7.1 \%(n=1)$ in the putamen, $14.3 \%(n=2)$ in the cerebellum and $28.6 \%(n=4)$ had UBOs in the WM. The frequency and distribution of UBOs is in accordance with published data [12]. None of the TD participants had UBOs. The number of UBOs was not correlated with total intracranial volume $(\mathrm{r}=0.056, P=0.850)$.

\section{Whole-brain analyses}

Children with NF1 showed a 10\% increase in total intracranial volume (TIV) as compared with the TD group (NF1: $1658 \pm 127 \mathrm{~cm}^{3}$; TD: $1505 \pm 138 \mathrm{~cm}^{3} ; \mathrm{t}_{(26)}=3.041$, $P=0.005)$. This overall increase was more attributable to an increase in WM (20\%) (NF1: $517 \pm 61 \mathrm{~cm}^{3}$; TD: $428 \pm$ $\left.46 \mathrm{~cm}^{3} ; \mathrm{t}_{(26)}=4.340, P<0.001\right)$ than GM (8\%), including cortical and subcortical GM (NF1: $789 \pm 78 \mathrm{~cm}^{3}$; TD: $\left.728 \pm 74 \mathrm{~cm}^{3} ; \mathrm{t}_{(26)}=2.104, P=0.045\right)$. After controlling for TIV, only WM remained different between groups $\left(\mathrm{WM}: \mathrm{F}_{(1,25)}=8.344, P=0.008 ; \mathrm{GM}: \mathrm{F}_{(1,25)}=1.044, P=\right.$ $0.317)$, Table 2 . Age was not significantly correlated with TIV for our subjects $(\mathrm{r}=0.067, P=0.736)$.

We next examined overall volumetric differences at the lobar level. Results for WM are displayed in Figure 1A. Group differences in WM were reflected by a main effect of group $\left(\mathrm{F}_{(1,25)}=8.028, P=0.009\right)$, two-way interactions between hemisphere and group $\left(\mathrm{F}_{(1,25)}=5.287, P=0.030\right)$ and lobe and group $\left(\mathrm{F}_{(3,75)}=6.758, P<0.001\right)$. Follow-up multivariate ANCOVA controlling for TIV, revealed that the left and right frontal lobes were significantly larger in patients (left frontal lobe: $\mathrm{F}_{(1,25)}=10.456, P=0.003$; right frontal lobe: $\left.\mathrm{F}_{(1,25)}=5.786, P=0.026\right)$, as well as left and right temporal lobes (left temporal lobe: $\mathrm{F}_{(1,25)}=10.930, P$ $=0.003$; right temporal lobe: $\left.\mathrm{F}_{(1,25)}=12.125, P=0.002\right)$. However only the left hemisphere parietal lobe was significantly larger (left parietal lobe: $\mathrm{F}_{(1,25)}=7.980, P=0.009$; right parietal lobe: $F_{(1,25)}=3.295, P=0.081$ ) and no 
Table 2 Results of whole-brain analyses

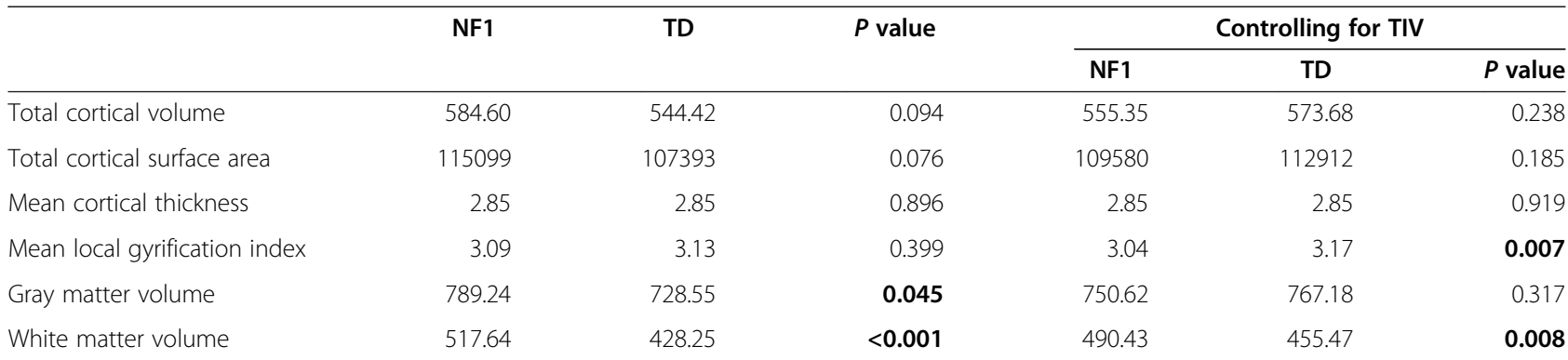

Mean values after controlling for total intracranial volume represent estimate marginal means. Bold represents significant results $(P<0.05)$. Volumes are expressed in $\mathrm{cm}^{3}$, surface in $\mathrm{mm}^{2}$, and thickness in $\mathrm{mm}$.

$\mathrm{NF} 1$ = neurofibromatosis type $1 ; \mathrm{TD}=$ typically developing; TIV = total intracranial volume.

differences were observed for the occipital lobe (left occipital lobe: $\mathrm{F}_{(1,25)}=0.078, P=0.782$; right occipital lobe: $\left.F_{(1,25)}=0.713, P=0.406\right)$. Results for $G M$ are displayed in Figure 1B. The lobar GM volumes included only cortical volumes and resulted in no significant effect of group and no interaction between group and lobe. Nonetheless, we found a significant two-way interaction between hemisphere and group $\left(\mathrm{F}_{(1,25)}=8.468, P=0.007\right)$.

At the cerebellar level, neither the cerebellar WM (left hemisphere: $\mathrm{F}_{(1,25)}=0.042, P=0.840$; right hemisphere: $\mathrm{F}_{(1,25)}=1.908, P=0.179$ ), nor the $\mathrm{GM}$ volumes (left hemisphere: $\mathrm{F}_{(1,25)}=0.331, P=0.570$; right hemisphere: $\left.F_{(1,25)}=0.612, P=0.441\right)$ were statistically different between patients and TD children.

Total cortical measurements of volume, thickness and surface area were not different between patients with NF1 and TD children. However, mean LGI is significantly reduced in patients with NF1 when the increased intracranial volume in the patient group is taken into account (see Table 2).

\section{Subcortical regional brain volumes}

Children with NF1 showed increased volumes of the thalami, the right caudate and the mid regions of the corpus callosum (mid-posterior, central, mid-anterior), Figure 2. These regions remained significant after correcting for multiple comparisons (FDR, $q=0.1$ ), Table 3 . Adding age or IQ as a covariates to the ANCOVA did not change the results.

\section{Cortical volume, cortical thickness and cortical surface area regional analyses}

Cortical volume group differences, investigated using repeated measures ANCOVA with TIV as covariate, resulted in no main effect of group $\left(\mathrm{F}_{(1,25)}=0.690, P=0.414\right)$, but statistically significant two-way interactions between region and group $\left(\mathrm{F}_{(33,825)}=1.651, P=0.013\right)$ and hemisphere and group $\left(\mathrm{F}_{(1,25)}=8.058, P=0.009\right)$. Repeated measures ANCOVA of cortical thickness measurements resulted in no statistically significant effect of group $\left(\mathrm{F}_{(1,25)}=1.084\right.$,
$P=0.308)$, but a significant effect of brain region $\left(\mathrm{F}_{(33,825)}=\right.$ 5.870, $P<0.001)$, a two-way interaction between region and group $\left(\mathrm{F}_{(33,825)}=1.522, P=0.031\right)$ and a three-way interaction between hemisphere, region and group $\left(\mathrm{F}_{(33,825)}=\right.$ 1.455, $P=0.049$ ). The results for cortical surface area resemble those found for cortical volume and cortical thickness, with no significant effect of group $\left(\mathrm{F}_{(1,25)}=\right.$ $0.378, P=0.544)$. Nevertheless, we observed a significant two-way interaction between hemisphere and group $\left(\mathrm{F}_{(1,25)}=6.061, P=0.021\right)$. Significant interactions observed for the regional cortical analyses were explored in multivariate ANCOVAs. However, none of these differences survived correction for multiple comparisons (FDR, $q=0.1$ ), Additional file 1: Table S1.

\section{Gyrification index}

The gyrification index showed a significant effect of group $\left(\mathrm{F}_{(1,25)}=10.400, P=0.003\right)$, an effect of region $\left(\mathrm{F}_{(33,825)}=\right.$ 3.263, $P<0.001)$ and a two-way interaction between region and group $\left(\mathrm{F}_{(33,825)}=2.591, P<0.001\right)$. Follow-up multivariate ANCOVA showed that patients with NF1 have reduced gyrification mainly in frontal and temporal lobar regions, but also in the insula, parietal, occipital and cingulate gyri, Table 4 and Figure 3. After correction for multiple comparisons several gyral regions remained statistically significant: left and right superior frontal, left and right superior temporal, right middle temporal and right transverse temporal (FDR, $q=0.05$ ). The majority of gyral regions remained significant at FDR, $q=0.1$ (Table 4). Adding age or IQ as covariates to the repeated measures ANCOVA and follow-up ANCOVAs did not change the results.

\section{Brain size and folding relationships}

In humans, the volume of the brain and the area of its cortical surface are strongly correlated [51]. This relation is such that larger brains are normally accompanied by a higher increase in surface area than would be expected by mere scaling of the brain. Furthermore, increased folding is necessary for compactness of connections $[52,53]$. 

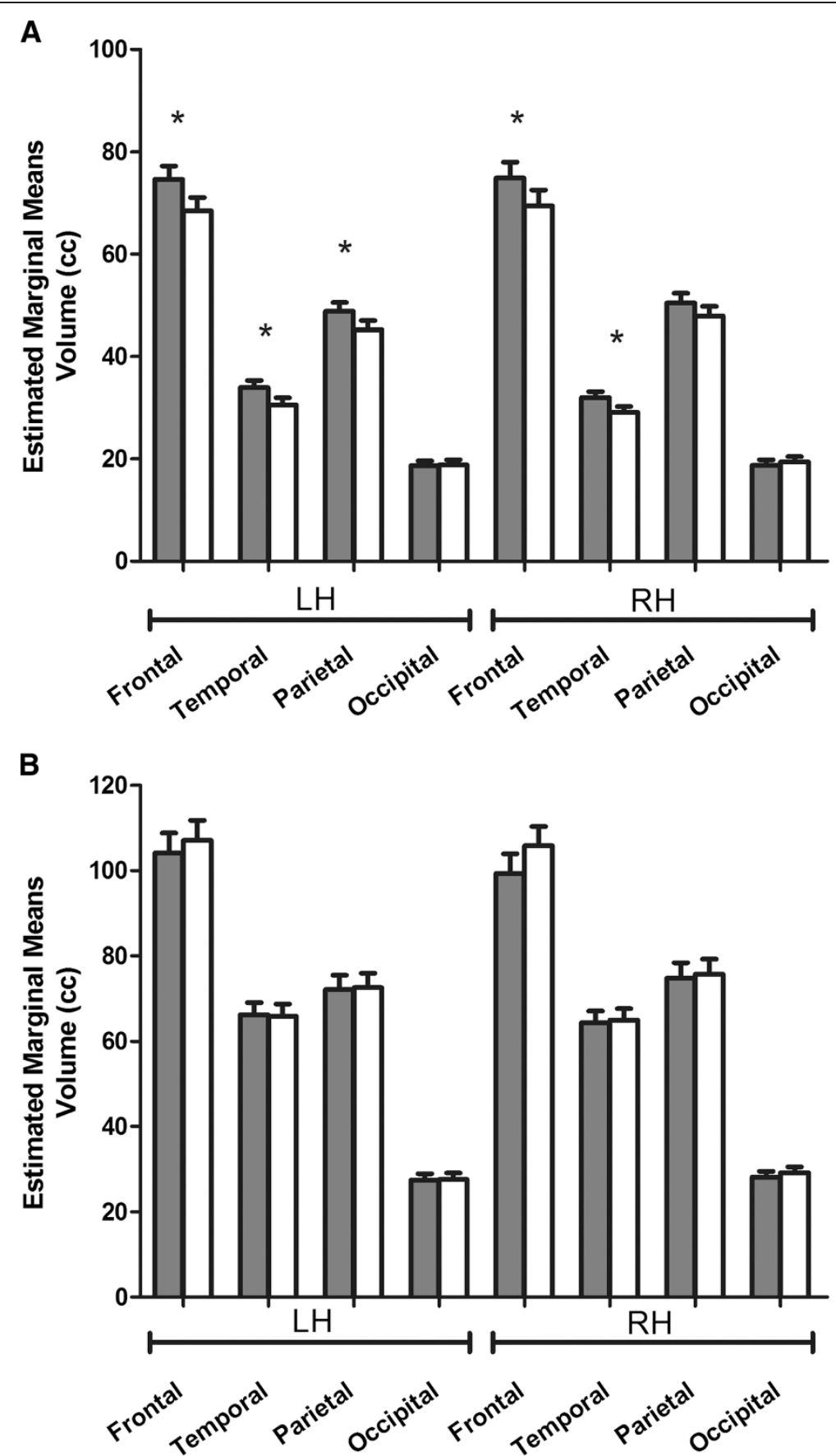

Figure 1 Lobar volumes in patients with neurofibromatosis type 1 (NF1) (gray bars) and typically developing children (white bars). Lobar volumes are displayed by hemisphere after controlling for total intracranial volume. (A) Lobar white matter. (B) Lobar gray matter. Graphs depict mean and $\mathrm{SEM},{ }^{*} P<0.05$. $\mathrm{LH}=$ left hemisphere; $\mathrm{RH}=$ right hemisphere.

Indeed, when brain volume and surface area are plotted in a logarithmic scale the slope of the regression line obtained indicates a disproportionate expansion of the cerebral cortex in relation to brain volume, a result that is related to increased gyrification. Therefore we investigated whether this relationship was preserved in NF1.
Figure 4A shows the relationship between cortical surface area and intracranial volume for patients with NF1 and TD children after controlling for age and gender, plotted in a log-log graph. TIV is correlated with surface area in both groups (NF1: $\mathrm{r}=0.765, P=0.004$; TD: $\mathrm{r}=$ $0.882, P<0.001)$. The slope of the regression line is 

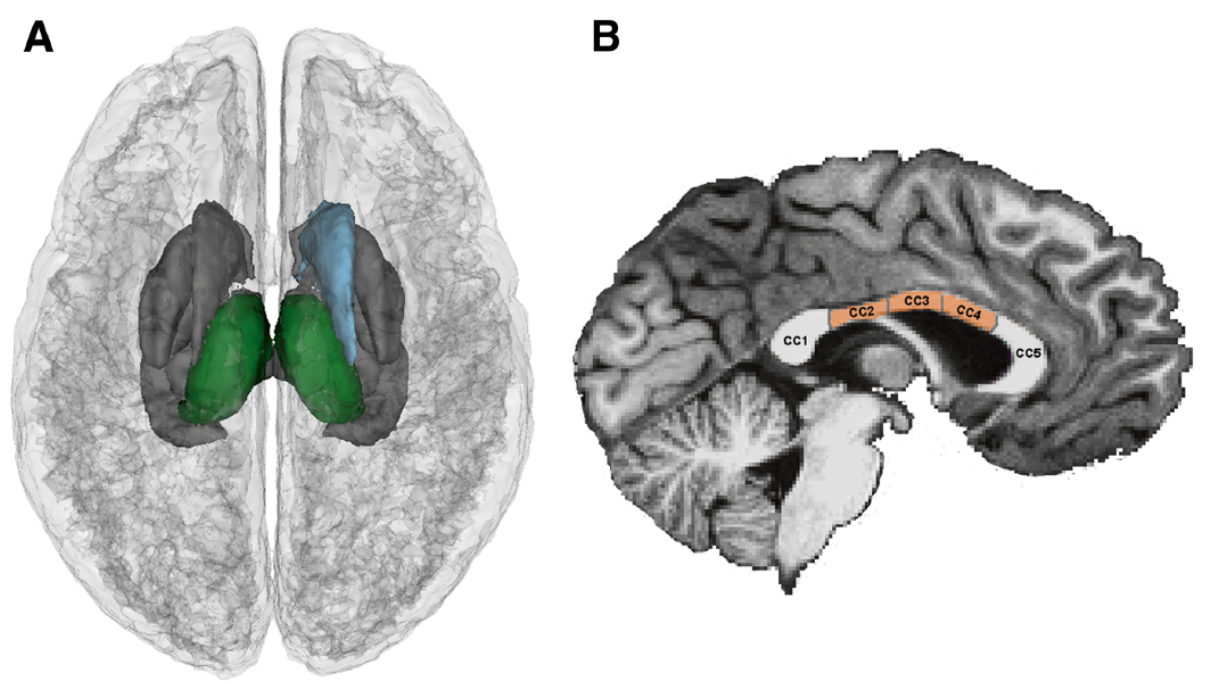

Figure 2 Group differences in subcortical regional brain volumes: superior view (A) and sagittal view showing the divisions for the corpus callosum (B). The larger volume in patients with neurofibromatosis type 1 (NF1) was observed in the left and right thalamus (green) and right caudate nucleus (blue) after controlling for total intracranial volume (TIV) and multiple comparisons using false discovery rate (FDR). In the corpus callosum, patients with NF1 showed larger volumes of the mid regions (mid-posterior, mid-anterior and central). CC = corpus callosum; CC1 = posterior; CC2 = mid-posterior; CC3 = central; CC4 = mid-anterior; CC5 = anterior.

0.928 for NF1 and 1.095 for TD children, higher than the value expected for an isometric scaling $(2 / 3)$ as observed in the human brain [51].

To investigate whether the degree of cortical folding is related with measurements of TIV, surface area and cortical thickness, we performed partial correlations between these variables, controlling for age and gender. LGI was only positively correlated with TIV for TD subjects (NF1: $\mathrm{r}=0.418, P=0.176$; TD: $\mathrm{r}=0.765, P=0.004$ ), Figure 4B. The cortical surface area was correlated with LGI for both groups (NF1: $\mathrm{r}=0.696, P=0.012$; TD: $\mathrm{r}=$ 0.877, $P<0.001)$, Figure $4 \mathrm{C}$; while LGI and cortical thickness were not correlated for any of the groups (not shown), consistent with prior studies [54-56].

\section{Discussion}

In this study, we used computational methods to examine the impact of NF1, a single gene disorder, on multidimensional morphological brain traits. This is the first study to examine measurements of cortical thickness, cortical surface area and gyrification in this common neurodevelopmental genetic condition. We confirmed that children with NF1 have larger intracranial volumes than typically developing children (approximately 10\%) and our findings indicate that this enlargement is mainly a result of increased WM volume. At the lobar level, our results indicate that patients with NF1 have larger WM volumes in the frontal lobe (consistent with prior studies [15,16,22]), temporal lobe (in agreement with voxel-based morphometry findings in a partly overlapping cohort [22]), and left parietal lobe. We did not find alterations in the occipital lobe. Our lobar data is in agreement with the notion that WM alterations are predominant in anterior brain regions. We also observed a parallel increase in GM volume in patients with NF1, a result attributable to larger subcortical rather than cortical volumes.

Measurements of subcortical regional volumes indicated that the thalami, the right caudate nucleus and the mid portions of the corpus callosum are significantly larger in patients with NF1 than TD children.

This study is the first, to the best of our knowledge, to report a volumetric alteration of the thalami in children with NF1. Moreover, we have previously identified this structure as belonging to a spatial pattern that significantly contributes to discriminate between brains from patients with NF1 and brains from controls [22]. Other studies have reported thalamic hypometabolism [20], $\mathrm{T}_{1}$ reduction [14] and abnormal choline content [21], possibly reflecting altered myelination.

The thalamus is a highly interactive structure with widespread connections to multiple cortical regions, and it provides selection and transformation of different sensory inputs to the cortex. The various nuclei of the thalamus are involved in the integration of sensory and motor information, memory and executive functions [57], competences in which NF1 patients show disabilities $[4,58,59]$.

The right caudate nucleus was also found to be larger in patients and it was previously identified as a relevant structure to discriminate between NF1 and control subjects [22]. The caudate is a nucleus of the basal ganglia and therefore plays a role in sensorimotor coordination, 
Table 3 Results of analysis of covariance (ANCOVA) in subcortical regions

\begin{tabular}{|c|c|c|c|c|}
\hline \multirow[t]{2}{*}{ Region } & \multirow[t]{2}{*}{ Hemisphere } & \multicolumn{3}{|c|}{ Volume } \\
\hline & & $\mathrm{F}$ & $P$ value & DoD \\
\hline \multirow[t]{2}{*}{ Thalamus } & L & 6.106 & $0.021^{a}$ & + \\
\hline & $\mathrm{R}$ & 9.415 & $0.005^{\mathrm{a}}$ & + \\
\hline \multirow[t]{2}{*}{ Caudate } & L & 3.468 & 0.074 & \\
\hline & $\mathrm{R}$ & 6.861 & $0.015^{\mathrm{a}}$ & + \\
\hline \multirow[t]{2}{*}{ Putamen } & $L$ & 0.610 & 0.442 & \\
\hline & $\mathrm{R}$ & 0.335 & 0.568 & \\
\hline \multirow[t]{2}{*}{ Pallidum } & $L$ & 0.344 & 0.563 & \\
\hline & $\mathrm{R}$ & 0.023 & 0.880 & \\
\hline \multirow[t]{2}{*}{ Hippocampus } & $L$ & 3.942 & 0.058 & \\
\hline & $\mathrm{R}$ & 0.108 & 0.746 & \\
\hline \multirow[t]{2}{*}{ Amygdala } & $L$ & 0.235 & 0.632 & \\
\hline & $\mathrm{R}$ & 1.358 & 0.255 & \\
\hline \multirow[t]{2}{*}{ Accumbens area } & $\mathrm{L}$ & 1.525 & 0.228 & \\
\hline & $\mathrm{R}$ & 3.140 & 0.089 & \\
\hline \multirow[t]{2}{*}{ Ventral diencephalon } & $\mathrm{L}$ & 4.242 & 0.050 & \\
\hline & $\mathrm{R}$ & 2.748 & 0.110 & \\
\hline CC posterior & & 3.676 & 0.067 & \\
\hline CC mid-posterior & & 5.587 & $0.026^{a}$ & + \\
\hline CC central & & 6.004 & $0.022^{\mathrm{a}}$ & + \\
\hline CC mid-anterior & & 8.919 & $0.006^{\mathrm{a}}$ & + \\
\hline CC anterior & & 2.902 & 0.101 & \\
\hline Brainstem & & 2.563 & 0.122 & \\
\hline
\end{tabular}

Bold represents significant results $(P<0.05)$.

${ }^{\text {a}}$ Represents significant results after correction for multiple comparisons with FDR $(q=0.1)$. A plus sign indicate the direction (upwards) of the group difference, $+=$ NF1 $>$ typically developing subjects.

$\mathrm{DoD}=$ direction of difference; $\mathrm{CC}=$ corpus callosum; $\mathrm{L}=$ left; $\mathrm{R}=$ right; $\mathrm{TIV}=$ total intracranial volume.

while there is also evidence accumulating indicative of an involvement in goal-directed behavior [60]. It is widely connected with the frontal lobe and particularly with the dorsolateral prefrontal cortex [61,62], which is involved in working memory and executive function. A recent functional MRI (fMRI) study showed abnormal right caudate activation in NF1 in a spatial working memory task [63]. Moreover, Schrimsher et al. [64] observed that children with a greater degree of right to left caudate volume asymmetry show subclinical inattentive behaviors that define attention-deficit hyperactivity disorder (ADHD). Interestingly, there is a high incidence of ADHD in NF1 [4].

Finally, the enlargement observed in the midline portion of the corpus callosum corroborates previous reports from our group, in a partly overlapping cohort, using an independent method [22] and others [14,31-34]. Besides morphometric abnormalities, there is evidence of altered microstructure of the corpus callous in NF1 $[65,66]$. Behaviorally, higher volumes of corpus callosum
Table 4 Results of analysis of covariance (ANCOVA) for local gyrification index in gyral regions

\begin{tabular}{|c|c|c|c|c|}
\hline \multirow[t]{2}{*}{ Gyral region } & \multirow[t]{2}{*}{ Hemisphere } & \multicolumn{3}{|c|}{ Local gyrification index } \\
\hline & & $F$ & $P$ value & DoD \\
\hline \multicolumn{5}{|l|}{ Frontal lobe } \\
\hline \multirow[t]{2}{*}{ Superior frontal } & $\mathrm{L}$ & 12.315 & $0.002^{b}$ & - \\
\hline & $\mathrm{R}$ & 11.938 & $0.002^{b}$ & - \\
\hline \multirow[t]{2}{*}{ Caudal middle frontal } & $L$ & 1.074 & 0.310 & \\
\hline & $\mathrm{R}$ & 5.046 & $0.034^{\mathrm{a}}$ & - \\
\hline \multirow[t]{2}{*}{ Rostral middle frontal } & $\mathrm{L}$ & 4.036 & 0.055 & \\
\hline & $\mathrm{R}$ & 1.870 & 0.184 & \\
\hline \multirow[t]{2}{*}{ Pars opercularis } & $L$ & 7.575 & $0.011^{a}$ & - \\
\hline & $\mathrm{R}$ & 4.071 & 0.054 & \\
\hline \multirow[t]{2}{*}{ Pars triangularis } & $\mathrm{L}$ & 3.860 & 0.061 & \\
\hline & $\mathrm{R}$ & 2.009 & 0.169 & \\
\hline \multirow[t]{2}{*}{ Pars orbitalis } & $\mathrm{L}$ & 8.324 & $0.008^{\mathrm{a}}$ & - \\
\hline & $\mathrm{R}$ & 4.869 & $0.037^{\mathrm{a}}$ & - \\
\hline \multirow[t]{2}{*}{ Lateral orbitofrontal } & $L$ & 7.702 & $0.010^{\mathrm{a}}$ & - \\
\hline & $\mathrm{R}$ & 1.797 & 0.192 & \\
\hline \multirow[t]{2}{*}{ Medial orbitofrontal } & $\mathrm{L}$ & 6.298 & $0.019^{a}$ & - \\
\hline & $\mathrm{R}$ & 4.472 & 0.045 & - \\
\hline \multirow[t]{2}{*}{ Precentral } & $\mathrm{L}$ & 5.693 & $0.025^{\mathrm{a}}$ & - \\
\hline & R & 6.354 & $0.018^{a}$ & - \\
\hline \multirow[t]{2}{*}{ Paracentral } & $\mathrm{L}$ & 5.165 & $0.032^{\mathrm{a}}$ & - \\
\hline & $\mathrm{R}$ & 2.847 & 0.104 & \\
\hline \multirow[t]{2}{*}{ Frontal pole } & $\mathrm{L}$ & 6.768 & $0.015^{\mathrm{a}}$ & - \\
\hline & $\mathrm{R}$ & 1.366 & 0.253 & \\
\hline \multicolumn{5}{|l|}{ Temporal lobe } \\
\hline \multirow[t]{2}{*}{ Superior temporal } & L & 11.052 & $0.003^{b}$ & - \\
\hline & $\mathrm{R}$ & 24.242 & $<0.001^{b}$ & - \\
\hline \multirow[t]{2}{*}{ Middle temporal } & $\mathrm{L}$ & 5.876 & $0.023^{a}$ & - \\
\hline & $\mathrm{R}$ & 18.742 & $<0.001^{b}$ & - \\
\hline \multirow[t]{2}{*}{ Inferior temporal } & $\mathrm{L}$ & 0.312 & 0.582 & \\
\hline & $\mathrm{R}$ & 4.855 & $0.037^{\mathrm{a}}$ & - \\
\hline \multirow[t]{2}{*}{ Entorhinal } & $\mathrm{L}$ & 2.504 & 0.126 & \\
\hline & $\mathrm{R}$ & 6.935 & $0.014^{a}$ & - \\
\hline \multirow[t]{2}{*}{ Fusiform } & $\mathrm{L}$ & 0.044 & 0.836 & \\
\hline & $\mathrm{R}$ & 1.095 & 0.305 & \\
\hline \multirow[t]{2}{*}{ Parahippocampal } & L & 0.013 & 0.911 & \\
\hline & $\mathrm{R}$ & 0.529 & 0.474 & \\
\hline \multirow[t]{2}{*}{ Temporal pole } & $\mathrm{L}$ & 3.399 & 0.077 & \\
\hline & $\mathrm{R}$ & 5.442 & $0.028^{a}$ & - \\
\hline \multirow[t]{2}{*}{ Transverse temporal } & $\mathrm{L}$ & 3.517 & 0.072 & \\
\hline & R & 14.003 & $0.001^{b}$ & - \\
\hline \multirow[t]{2}{*}{ Banks superior temporal sulcus } & $L$ & 0.190 & 0.667 & \\
\hline & $\mathrm{R}$ & 5.689 & $0.025^{\mathrm{a}}$ & - \\
\hline
\end{tabular}


Table 4 Results of analysis of covariance (ANCOVA) for local gyrification index in gyral regions (Continued)

\begin{tabular}{|c|c|c|c|c|}
\hline \multicolumn{5}{|l|}{ Parietal lobe } \\
\hline \multirow[t]{2}{*}{ Superior parietal } & $\mathrm{L}$ & 1.640 & 0.212 & \\
\hline & $\mathrm{R}$ & 0.125 & 0.727 & \\
\hline \multirow[t]{2}{*}{ Inferior parietal } & L & 0.220 & 0.643 & \\
\hline & $\mathrm{R}$ & 1.463 & 0.238 & \\
\hline \multirow[t]{2}{*}{ Supramarginal } & $L$ & 2.117 & 0.158 & \\
\hline & $\mathrm{R}$ & 5.233 & $0.031^{\mathrm{a}}$ & - \\
\hline \multirow[t]{2}{*}{ Postcentral } & $\mathrm{L}$ & 6.597 & $0.017^{\mathrm{a}}$ & - \\
\hline & $\mathrm{R}$ & 9.344 & $0.005^{\mathrm{a}}$ & - \\
\hline \multirow[t]{2}{*}{ Precuneus } & $\mathrm{L}$ & 3.117 & 0.090 & \\
\hline & $\mathrm{R}$ & 3.762 & 0.064 & \\
\hline \multicolumn{5}{|l|}{ Occipital lobe } \\
\hline \multirow[t]{2}{*}{ Lateral occipital } & $\mathrm{L}$ & 0.719 & 0.405 & \\
\hline & $\mathrm{R}$ & 0.498 & 0.487 & \\
\hline \multirow[t]{2}{*}{ Lingual } & L & 0.253 & 0.620 & \\
\hline & $\mathrm{R}$ & 2.862 & 0.103 & \\
\hline \multirow[t]{2}{*}{ Cuneus } & L & 3.589 & 0.070 & \\
\hline & $\mathrm{R}$ & 4.317 & 0.048 & - \\
\hline \multirow[t]{2}{*}{ Pericalcarine } & $L$ & 1.915 & 0.179 & \\
\hline & $\mathrm{R}$ & 5.044 & $0.034^{\mathrm{a}}$ & - \\
\hline \multirow[t]{2}{*}{ Rostral anterior cingulate } & $\mathrm{L}$ & 4.848 & $0.037^{\mathrm{a}}$ & - \\
\hline & $\mathrm{R}$ & 5.487 & $0.027^{\mathrm{a}}$ & - \\
\hline \multirow[t]{2}{*}{ Caudal anterior cingulate } & $L$ & 6.789 & $0.015^{\mathrm{a}}$ & - \\
\hline & $\mathrm{R}$ & 3.213 & 0.085 & \\
\hline \multirow[t]{2}{*}{ Posterior cingulate } & $L$ & 2.052 & 0.164 & \\
\hline & $\mathrm{R}$ & 3.165 & 0.087 & \\
\hline \multirow[t]{2}{*}{ Isthmus cingulate } & L & 0.213 & 0.648 & \\
\hline & $\mathrm{R}$ & 2.808 & 0.106 & \\
\hline \multirow[t]{2}{*}{ Insula } & L & 7.013 & $0.014^{\mathrm{a}}$ & - \\
\hline & $\mathrm{R}$ & 5.616 & $0.026^{\mathrm{a}}$ & - \\
\hline
\end{tabular}

Bold represents significant results $(P<0.05)$.

${ }^{\mathrm{a}}$ and ${ }^{\mathrm{b}}$ Represent significant results after correction for multiple comparisons with false discovery rate (FDR), ${ }^{\mathrm{a}}(q=0.1)$ and ${ }^{\mathrm{b}}(q=0.05$ or 0.1$)$. Minus indicates the direction of the group difference, - = NF1 < typically developing subjects.

$\mathrm{DoD}=$ direction of difference; $L=$ left; $R=$ right.

were previously related to low IQ, impaired visuospatial and motor skills and learning problems in children with NF1 [17,34]. Interestingly, we observed that the volume of the corpus callosum remains abnormal even for normal IQs.

Unlike the specific observations concerning subcortical structures, examination of cortical measurements indicated that alterations in cortical volume, cortical surface area and cortical thickness are not significant. Gyrification index was the only changed measure in cortex.
One of the most evident features of human evolution is the increase in brain size [67]. In response to evolutionary demands, a high level of gyrification occurred in parallel with an increase in cortical GM in order to maximize the cortical surface while maintaining a smaller intracranial size [68]. The increase in folding in bigger brains seems to be necessary for the formation of efficient corticocortical connections in larger volumes $[52,53]$. This evolutionary trait appears disrupted in NF1, with an increase in brain size without a corresponding adaptive increase in folding. Accordingly, the correlation observed in TD children between LGI and intracranial volume is absent in NF1, indicating that patients with NF1 present lower gyrification indices than would be expected for their brain volume. The phylogenetic development of gyral and sulcal folds likely optimizes compaction of neuronal fibers while keeping neuronal signaling at an efficient transit time [52,53]. Given that abnormal cortical folding may reflect deficits in structural and, consequently, functional cortical connectivity, we will speculate on potential links between cortical folding abnormalities and the patterns of cognitive dysfunction that characterize the NF1 phenotype.

Concerning the cognitive phenotype related to cortical functions, executive functions have been reported to be impaired in children with NF1 $[59,69]$, even when controlling for IQ [59]. Here, we observed lower LGI in several frontal lobe regions that could underlie executive impairments, namely the superior frontal gyri [70], right frontal pole [71] and orbitofrontal regions [72,73]. Moreover, the anterior cingulate cortex was also found to have lower LGI values in NF1 and it plays a role in attention and error detection [74]. Interestingly, we have previously found an abnormal activity pattern in this region using an overlapping cohort of subjects [35], possibly related with a deficit in default-mode network function.

Patients with NF1 have deficits in expressive and receptive language, vocabulary and phonologic awareness [58]. Previously, a correlation has been reported between verbal skills in NF1 and the inferior frontal gyrus morphology, such that individuals with 'typical' gyral patterns in the right hemisphere performed worse across language measures than those showing 'atypical' gyrus [75]. Here, we observed a deficit in gyrification in regions involved with language functions, namely in regions belonging to the Broca's complex (pars opercularis, pars orbitalis, pars triangularis) [76,77], superior temporal gyrus and middle temporal gyrus [78,79] and supramarginal gyrus [80,81]. Moreover, right transverse temporal gyrus, known as the Heschl's gyrus, also presented lower LGIs in patients. Abnormalities in the inferior frontal gyrus and Heschl's gyrus were associated with performance across language and neuropsychological measures in individuals with NF1 [75]. 

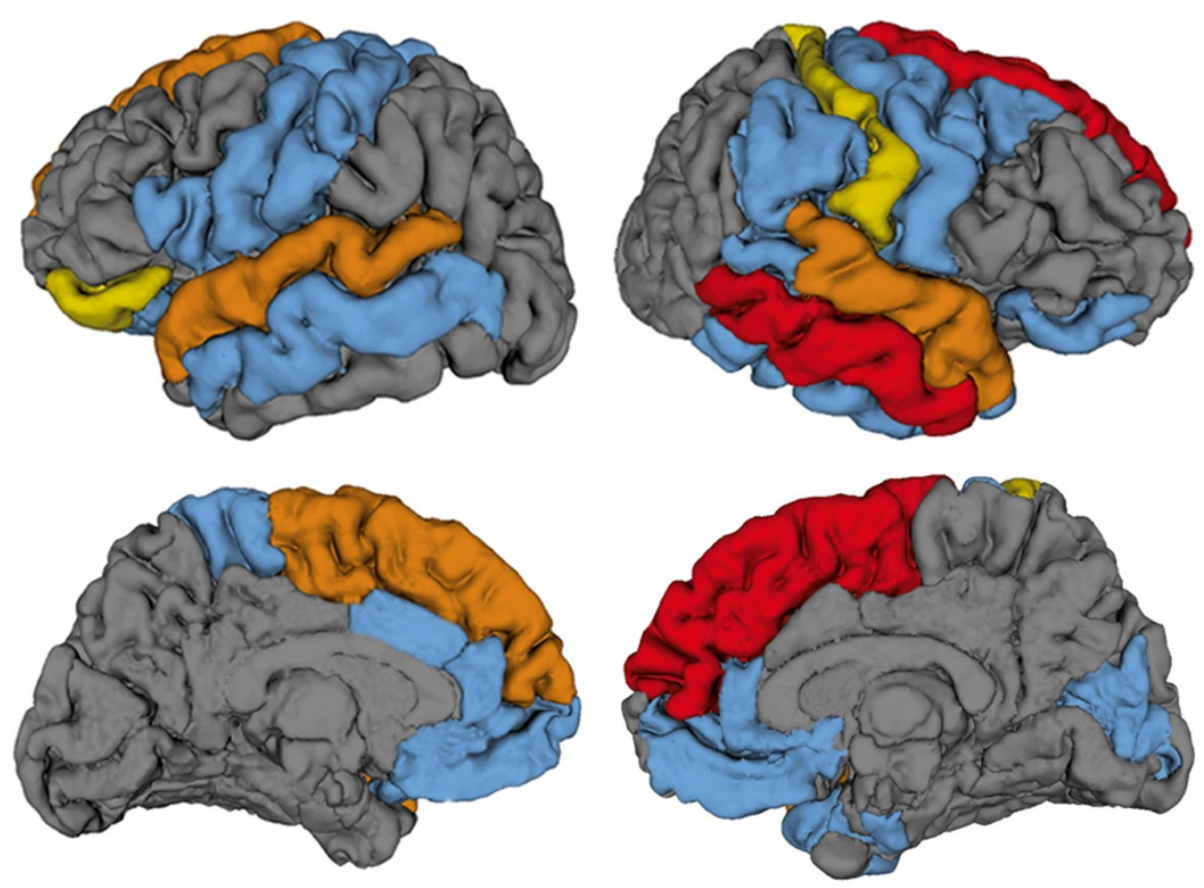

$p$ value

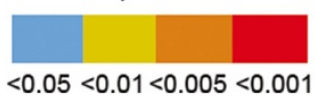

Figure 3 Graphical illustration of significant reductions in gyrification in patients with neurofibromatosis type 1 (NF1). This figure shows an overlay of F-test statistics (with $P$ values indicated by the color bar) where patients with NF1 have lower local gyrification index than typically developing children. Between-group comparisons were performed controlling for intracranial volume. Blue color depicts gyri with significant group differences at $P<0.05$, not corrected; yellow $P<0.01$ and orange $P<0.005$, both surviving correction for multiple comparisons with FDR $q=0.1$; red gyri $P<0.001$, survives correction for multiple comparisons with FDR $q<0.05$.

Motor deficits for both simple and complex motor tasks have been reported in NF1 $[58,82,83]$ consistent with the observed bilateral deficits in LGI in both precentral and paracentral gyri, underlying motor functions [84].

In spite of our identification of altered patterns of gyrification in regions underlying cognitive deficits typically observed in children with NF1, this was not the case for the posterior parietal lobe. This is rather surprising given that visuospatial deficits are considered a hallmark of the NF1 cognitive phenotype. This might be explained by the suggestion that other brain regions such as frontoexecutive regions contribute to the pattern of impairment observed in specific visuospatial tests (that is, judgment of line orientation test).
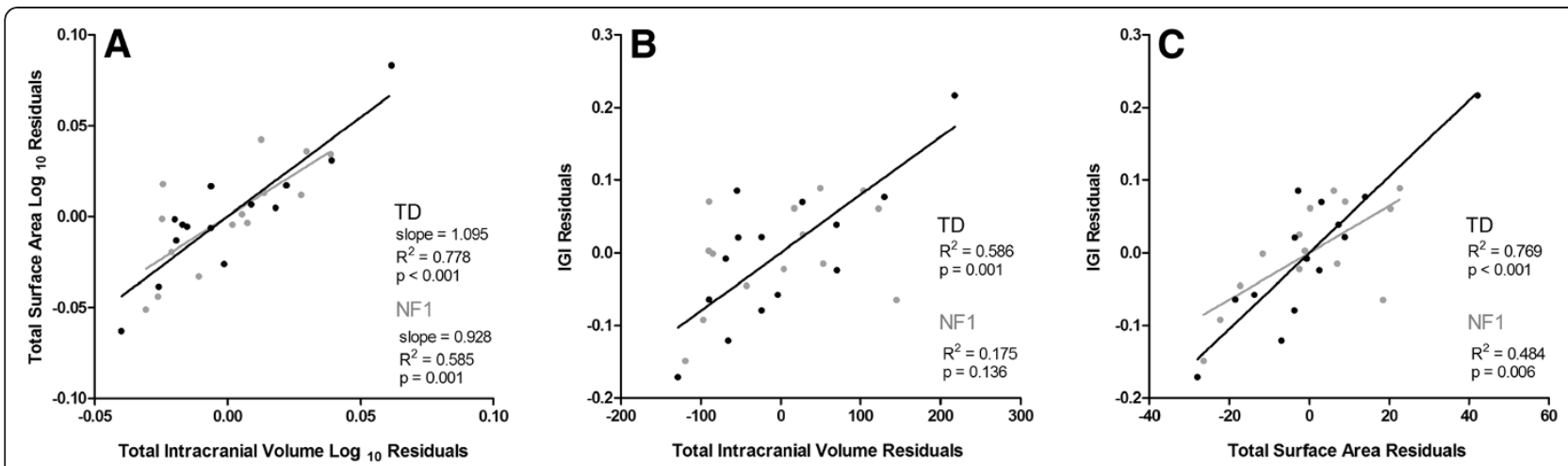

Figure 4 Brain size and folding relationships in neurofibromatosis type 1 (NF1) (gray) and typically developing children (TD) (black), taking into account age and gender. (A) Cortical surface area versus intracranial volume (log-log graph). (B) Local gyrification index (LGI) versus intracranial volume. (C) LGI versus surface area. 
In agreement with the notion of impaired low-level visual processing in NF1 $[35,85]$, we observed lower LGI in the right cuneus and pericalcarine regions.

It is estimated that around 30\% of phenotypic variance in gyrification is attributed to genetic variation [86]. Therefore, the observed reductions in LGI point towards early abnormalities in control over neuronal migration or proliferation. Deeper fissures develop earlier and are more strongly influenced by genetic processes and thus might be less susceptible to environmental perturbations. Insular sulci and the central sulcus are among the first macroscopical structures identified on the human fetal brain $[87,88]$, and both the insula and the gyri surrounding the central sulcus presented less gyrification in NF1 than TD individuals.

The mechanisms that drive cortical folding remain poorly understood and there are different possible explanations for the observed abnormalities of cortical gyrification in NF1. The two most widely accepted hypothesis to explain gyrification are: (1) folding is caused by differential growth of the cortex and (2) folding is caused by mechanical tension generated in axons. The first model proposes that differential growth rates of cortical layers directly affect the degree of cortical convolutions [89]. An alternate theory to this hypothesis suggests that changes in subcortical connections can lead to altered cortical folding patterns without changing the area of the cortical surface [90]. The second model, based on tensionbased cortical morphogenesis, proposes that the mechanical tension along axons is the driving force for cortical folding [91]. In line with this theory, we observed a significant increase in WM in the anterior NF1 brain accompanied by an enlargement of the corpus callosum. Moreover, diffusion tensor imaging studies showed altered microstructure in several white matter regions [66]. Both models are not necessarily contradictory and could jointly explain the gyral abnormalities in NF1.

The main limitation of the present study is that we investigated a large age range and we were limited to a relatively small number of participants. In that sense, longitudinal studies are clearly warranted to disentangle the complex genetic and non-genetic influences that contribute to the neuroanatomic and cognitive abnormalities in NF1.

\section{Conclusions}

We found that the overall increase in intracranial volume in patients with NF1 can be explained by an enlarged WM volume in anterior brain regions and subcortical GM volumes, with a disproportionate increase in the volumes of the thalami, right caudate nucleus and corpus callosum. At the cortical level we observed abnormalities of gyrification, which could reflect developmental abnormalities in both cortical architecture and corticocortical connectivity.
This newly identified pattern of gyral malformation required quantitative tools such as LGI to be detected. Given the emphasis on a careful matching between patients and TD children we believe that the brain alterations observed in here are shaped primarily by genetically programmed anomalous neurodevelopment. The fact that neuroanatomic abnormalities in patients with NF1 are localized to particular brain regions adds to the growing body of evidence that specific genes independently control the morphometry of specific cytoarchitectonic areas.

\section{Additional file}

Additional file 1: Supplementary material.

\section{Competing interests}

The authors have no financial or non-financial competing interests to declare.

\section{Authors' contributions}

IRV, MJR, ES and MCB conceptualized and designed the study. IRV collected and analyzed the data. All authors contributed to interpreting results and writing the manuscript. All authors read and approved the final manuscript.

\section{Acknowledgements}

We thank all the participants and their families for their involvement in this study. The authors wish to acknowledge the contributions of Carlos Ferreira and João Marques in technical assistance with scanning. This work was supported by the University of Coimbra (grant number III/14/2008) and the Portuguese Foundation for Science and Technology (grant numbers PIC/IC/ 83155/2007, PIC/IC/82986/2007, PTDC/SAU-ORG/118380, individual fellowships SFRH/BD/41348/2007 to IRV, SFRH/BPD/34392/2006 to MJR).

\section{Author details}

${ }^{1}$ Institute for Biomedical Imaging and Life Sciences, Faculty of Medicine, University of Coimbra, Azinhaga de Santa Comba, Coimbra 3000-548, Portugal. ${ }^{2}$ Department of Ophthalmology, Centro Hospitalar e Universitário de Coimbra, EPE, Av. Bissaya Barreto, Coimbra 3000-075, Portugal.

Received: 1 August 2012 Accepted: 22 January 2013

Published: 13 February 2013

\section{References}

1. Rakic P, Kornack DR: The Development and Evolutionary Expansion of the Cerebral Cortex in Primates. In Evolution of Nervous Systems. Edited by Kaas JH. Oxford: Academic Press; 2007:243-259.

2. Thompson PM, Cannon TD, Narr KL, van Erp T, Poutanen VP, Huttunen M, Lonnqvist J, Standertskjold-Nordenstam CG, Kaprio J, Khaledy M, Dail R, Zoumalan Cl, Toga AW: Genetic influences on brain structure. Nat Neurosci 2001, 4:1253-1258.

3. Kayl AE, Moore BD 3rd: Behavioral phenotype of neurofibromatosis, type 1. Ment Retard Dev Disabil Res Rev 2000, 6:117-124.

4. Hyman SL, Shores A, North KN: The nature and frequency of cognitive deficits in children with neurofibromatosis type 1. Neurology 2005, 65:1037-1044

5. Ferner RE: Neurofibromatosis 1 and neurofibromatosis 2: a twenty first century perspective. Lancet Neurol 2007, 6:340-351.

6. Daston MM, Ratner N: Neurofibromin, a predominantly neuronal GTPase activating protein in the adult, is ubiquitously expressed during development. Dev Dyn 1992, 195:216-226.

7. Zhu Y, Guignard F, Zhao D, Liu L, Burns DK, Mason RP, Messing A, Parada LF: Early inactivation of p53 tumor suppressor gene cooperating with NF1 loss induces malignant astrocytoma. Cancer Cell 2005, 8:119-130.

8. Lush ME, Li Y, Kwon CH, Chen J, Parada LF: Neurofibromin is required for barrel formation in the mouse somatosensory cortex. J Neurosci 2008, 28:1580-1587 
9. Hegedus B, Dasgupta B, Shin JE, Emnett RJ, Hart-Mahon EK, Elghazi L, Bernal-Mizrachi E, Gutmann DH: Neurofibromatosis-1 regulates neuronal and glial cell differentiation from neuroglial progenitors in vivo by both cAMP- and Ras-dependent mechanisms. Cell Stem Cell 2007, 1:443-457.

10. Yunoue S, Tokuo H, Fukunaga K, Feng L, Ozawa T, Nishi T, Kikuchi A, Hattori S, Kuratsu J, Saya H, Araki N: Neurofibromatosis type I tumor suppressor neurofibromin regulates neuronal differentiation via its GTPase-activating protein function toward Ras. J Bio/ Chem 2003, 278:26958-26969.

11. Fernandez-Medarde A, Santos E: The RasGrf family of mammalian guanine nucleotide exchange factors. Biochim Biophys Acta 2011, 1815:170-188.

12. Payne JM, Moharir MD, Webster R, North KN: Brain structure and function in neurofibromatosis type 1: current concepts and future directions. $J$ Neurol Neurosurg Psychiatry 2010, 81:304-309.

13. Said SM, Yeh TL, Greenwood RS, Whitt JK, Tupler LA, Krishnan KR: MRI morphometric analysis and neuropsychological function in patients with neurofibromatosis. Neuroreport 1996, 7:1941-1944.

14. Steen RG, Taylor JS, Langston JW, Glass JO, Brewer VR, Reddick WE, Mages $R$, Pivnick EK: Prospective evaluation of the brain in asymptomatic children with neurofibromatosis type 1: relationship of macrocephaly to $\mathrm{T} 1$ relaxation changes and structural brain abnormalities. AJNR Am J Neuroradiol 2001, 22:810-817.

15. Cutting LE, Huang GH, Zeger S, Koth CW, Thompson RE, Denckl MB: Growth curve analyses of neuropsychological profiles in children with neurofibromatosis type 1: specific cognitive tests remain "spared" and "impaired" over time. J Int Neuropsychol Soc 2002, 8:838-846.

16. Greenwood RS, Tupler LA, Whitt JK, Buu A, Dombeck CB, Harp AG, Payne ME, Eastwood JD, Krishnan KR, MacFall JR: Brain morphometry, T2weighted hyperintensities, and IQ in children with neurofibromatosis type 1. Arch Neurol 2005, 62:1904-1908.

17. Moore BD 3rd, Slopis JM, Jackson EF, De Winter AE, Leeds NE: Brain volume in children with neurofibromatosis type 1: relation to neuropsychological status. Neurology 2000, 54:914-920.

18. DiMario FJ Jr, Ramsby GR, Burleson JA: Brain morphometric analysis in neurofibromatosis 1. Arch Neurol 1999, 56:1343-1346.

19. Billingsley RL, Schrimsher GW, Jackson EF, Slopis JM, Moore BD 3rd: Significance of planum temporale and planum parietale morphologic features in neurofibromatosis type 1. Arch Neurol 2002, 59:616-622.

20. Kaplan AM, Chen $\mathrm{K}$, Lawson MA, Wodrich DL, Bonstelle $C T$, Reiman EM: Positron emission tomography in children with neurofibromatosis-1. J Child Neurol 1997, 12:499-506.

21. Wang PY, Kaufmann WE, Koth CW, Denckla MB, Barker PB: Thalamic involvement in neurofibromatosis type 1: evaluation with proton magnetic resonance spectroscopic imaging. Ann Neurol 2000, 47:477-484.

22. Duarte JV, Ribeiro MJ, Violante IR, Cunha G, Silva E, Castelo-Branco M: Multivariate pattern analysis reveals subtle brain anomalies relevant to the cognitive phenotype in neurofibromatosis type 1. Hum Brain Mapp 2012, doi:10.1002/hbm.22161. Epub ahead of print.

23. Rakic P: A small step for the cell, a giant leap for mankind: a hypothesis of neocortical expansion during evolution. Trends Neurosci 1995, 18:383-388.

24. Armstrong E, Curtis M, Buxhoeveden DP, Fregoe C, Zilles K, Casanova MF, McCarthy WF: Cortical gyrification in the rhesus monkey: a test of the mechanical folding hypothesis. Cereb Cortex 1991, 1:426-432.

25. Raznahan A, Shaw P, Lalonde F, Stockman M, Wallace GL, Greenstein D, Clasen L, Gogtay N, Giedd JN: How does your cortex grow? J Neurosci 2011, 31:7174-7177.

26. Panizzon MS, Fennema-Notestine C, Eyler LT, Jernigan $T L$, Prom-Wormley E, Neale M, Jacobson K, Lyons MJ, Grant MD, Franz CE, Xian H, Tsuang M, Fischl B, Seidman L, Dale A, Kremen WS: Distinct genetic influences on cortical surface area and cortical thickness. Cereb Cortex 2009, 19:2728-2735.

27. Luders E, Narr KL, Thompson PM, Rex DE, Woods RP, Deluca H, Jancke L, Toga AW: Gender effects on cortical thickness and the influence of scaling. Hum Brain Mapp 2006, 27:314-324.

28. Luders E, Narr KL, Bilder RM, Szeszko PR, Gurbani MN, Hamilton L, Toga AW, Gaser C: Mapping the relationship between cortical convolution and intelligence: effects of gender. Cereb Cortex 2008, 18:2019-2026.

29. Shaw P, Greenstein D, Lerch J, Clasen L, Lenroot R, Gogtay N, Evans A, Rapoport J, Giedd J: Intellectual ability and cortical development in children and adolescents. Nature 2006, 440:676-679.

30. Narr KL, Bilder RM, Luders E, Thompson PM, Woods RP, Robinson D, Szeszko PR, Dimtcheva T, Gurbani M, Toga AW: Asymmetries of cortical shape: effects of handedness, sex and schizophrenia. Neuroimage 2007, 34:939-948.
31. Cutting LE, Cooper KL, Koth CW, Mostofsky SH, Kates WR, Denckla MB, Kaufmann WE: Megalencephaly in NF1: predominantly white matter contribution and mitigation by ADHD. Neurology 2002, 59:1388-1394.

32. Dubovsky EC, Booth TN, Vezina G, Samango-Sprouse CA, Palmer KM Brasseux CO: MR imaging of the corpus callosum in pediatric patients with neurofibromatosis type 1. AJNR Am J Neuroradio/ 2001, 22:190-195.

33. Kayl AE, Moore BD 3rd, Slopis JM, Jackson EF, Leeds NE: Quantitative morphology of the corpus callosum in children with neurofibromatosis and attention-deficit hyperactivity disorder. J Child Neurol 2000, 15:90-96.

34. Pride N, Payne JM, Webster R, Shores EA, Rae C, North KN: Corpus callosum morphology and its relationship to cognitive function in neurofibromatosis type 1. J Child Neurol 2010, 25:834-841.

35. Violante IR, Ribeiro MJ, Cunha G, Bernardino I, Duarte JV, Ramos F, Saraiva J, Silva E, Castelo-Branco M: Abnormal Brain Activation in Neurofibromatosis Type 1: A Link between Visual Processing and the Default Mode Network. PLoS One 2012, 7:e38785

36. National Institutes of Health Consensus Development Conference: Neurofibromatosis. Conference statement. National Institutes of Health Consensus Development Conference. Arch Neurol 1988, 45:575-578.

37. Ozonoff S: Cognitive impairment in neurofibromatosis type 1. Am J Med Genet 1999, 89:45-52.

38. Wechsler D: Escala de Inteligência para Crianças - Terceira Edição (WISC-III): Manual. Lisboa, Portugal: Cegoc-Tea; 2003.

39. Dale AM, Fischl B, Sereno Ml: Cortical surface-based analysis. I. Segmentation and surface reconstruction. Neuroimage 1999, 9:179-194.

40. Fischl B, Dale AM: Measuring the thickness of the human cerebral cortex from magnetic resonance images. Proc Natl Acad Sci U S A 2000, 97:11050-11055

41. Fischl B, Salat DH, Busa E, Albert M, Dieterich M, Haselgrove C, van der Kouwe A, Killiany R, Kennedy D, Klaveness S, Montillo A, Makris N, Rosen B, Dale AM: Whole brain segmentation: automated labeling of neuroanatomical structures in the human brain. Neuron 2002, 33:341-355.

42. Fischl B, Salat DH, van der Kouwe AJ, Makris N, Segonne F, Quinn BT, Dale AM: Sequence-independent segmentation of magnetic resonance images. Neuroimage 2004, 23(Suppl 1):S69-84

43. Fischl B, Liu A, Dale AM: Automated manifold surgery: constructing geometrically accurate and topologically correct models of the human cerebral cortex. IEEE Trans Med Imaging 2001, 20:70-80.

44. Segonne F, Pacheco J, Fischl B: Geometrically accurate topologycorrection of cortical surfaces using nonseparating loops. IEEE Trans Med Imaging 2007, 26:518-529.

45. Fischl B, Sereno MI, Tootell RB, Dale AM: High-resolution intersubject averaging and a coordinate system for the cortical surface. Hum Brain Mapp 1999, 8:272-284

46. Schaer M, Cuadra MB, Tamarit L, Lazeyras F, Eliez S, Thiran JP: A surfacebased approach to quantify local cortical gyrification. IEEE Trans Med Imaging 2008, 27:161-170.

47. Desikan RS, Segonne F, Fischl B, Quinn BT, Dickerson BC, Blacker D, Buckner RL, Dale AM, Maguire RP, Hyman BT, Albert MS, Killiany RJ: An automated labeling system for subdividing the human cerebral cortex on MRI scans into gyral based regions of interest. Neuroimage 2006, 31:968-980.

48. Buckner RL, Head D, Parker J, Fotenos AF, Marcus D, Morris JC, Snyder AZ: A unified approach for morphometric and functional data analysis in young, old, and demented adults using automated atlas-based head size normalization: reliability and validation against manual measurement of total intracranial volume. Neuroimage 2004, 23:724-738.

49. Salat DH, Greve DN, Pacheco JL, Quinn BT, Helmer KG, Buckner RL, Fischl B: Regional white matter volume differences in nondemented aging and Alzheimer's disease. Neuroimage 2009, 44:1247-1258.

50. Benjamini $Y$, Hochberg Y: Controlling the False Discovery Rate - a Practical and Powerful Approach to Multiple Testing. Journal of the Royal Statistical Society Series B-Methodological 1995, 57:289-300.

51. Toro R, Perron M, Pike B, Richer L, Veillette S, Pausova Z, Paus T: Brain size and folding of the human cerebral cortex. Cereb Cortex 2008, 18:2352-2357.

52. Murre JM, Sturdy DP: The connectivity of the brain: multi-level quantitative analysis. Biol Cybern 1995, 73:529-545.

53. Ruppin E, Schwartz EL, Yeshurun Y: Examining the volume efficiency of the cortical architecture in a multi-processor network model. Biol Cybern 1993, 70:89-94.

54. Bearden CE, van Erp TG, Dutton RA, Lee AD, Simon TJ, Cannon TD, Emanuel BS, McDonald-McGinn D, Zackai EH, Thompson PM: Alterations in midline 
cortical thickness and gyrification patterns mapped in children with 22q11.2 deletions. Cereb Cortex 2009, 19:115-126.

55. Lin JJ, Salamon N, Lee AD, Dutton RA, Geaga JA, Hayashi KM, Luders E, Toga AW, Engel J Jr, Thompson PM: Reduced neocortical thickness and complexity mapped in mesial temporal lobe epilepsy with hippocampal sclerosis. Cereb Cortex 2007, 17:2007-2018.

56. Thompson PM, Lee AD, Dutton RA, Geaga JA, Hayashi KM, Eckert MA, Bellugi U, Galaburda AM, Korenberg JR, Mills DL, Toga AW, Reiss AL: Abnormal cortical complexity and thickness profiles mapped in Williams syndrome. J Neurosci 2005, 25:4146-4158.

57. Schmahmann JD, Pandya DN: Disconnection syndromes of basal ganglia, thalamus, and cerebrocerebellar systems. Cortex 2008, 44:1037-1066.

58. Levine TM, Materek A, Abel J, O'Donnell M, Cutting LE: Cognitive profile of neurofibromatosis type 1. Semin Pediatr Neurol 2006, 13:8-20.

59. Roy A, Roulin JL, Charbonnier V, Allain P, Fasotti L, Barbarot S, Stalder JF, Terrien A, Le Gall D: Executive dysfunction in children with neurofibromatosis type 1: a study of action planning. J Int Neuropsychol Soc 2010, 16:1056-1063.

60. Grahn JA, Parkinson JA, Owen AM: The cognitive functions of the caudate nucleus. Prog Neurobiol 2008, 86:141-155.

61. Kemp JM, Powell TP: The cortico-striate projection in the monkey. Brain 1970, 93:525-546.

62. Yeterian EH, Van Hoesen GW: Cortico-striate projections in the rhesus monkey: the organization of certain cortico-caudate connections. Brain Res 1978, 139:43-63.

63. Shilyansky C, Karlsgodt KH, Cummings DM, Sidiropoulou K, Hardt M, James $A S$, Ehninger D, Bearden CE, Poirazi P, Jentsch JD, Cannon TD, Levine MS, Silva AJ: Neurofibromin regulates corticostriatal inhibitory networks during working memory performance. Proc Natl Acad Sci U S A 2010, 107:13141-13146.

64. Schrimsher GW, Billingsley RL, Jackson EF, Moore BD 3rd: Caudate nucleus volume asymmetry predicts attention-deficit hyperactivity disorder (ADHD) symptomatology in children. J Child Neurol 2002, 17:877-884

65. Wignall EL, Griffiths PD, Papadakis NG, Wilkinson ID, Wallis LI, Bandmann O, Cowell PE, Hoggard N: Corpus callosum morphology and microstructure assessed using structural MR imaging and diffusion tensor imaging: initial findings in adults with neurofibromatosis type 1. AJNR Am J Neuroradiol 2010, 31:856-861.

66. Zamboni SL, Loenneker T, Boltshauser E, Martin E, II'yasov KA: Contribution of diffusion tensor MR imaging in detecting cerebral microstructural changes in adults with neurofibromatosis type 1. AJNR Am J Neuroradiol 2007, 28:773-776.

67. Passingham RE: Anatomical differences between the neocortex of man and other primates. Brain Behav Evol 1973, 7:337-359.

68. Zilles K, Armstrong E, Schleicher A, Kretschmann HJ: The human pattern of gyrification in the cerebral cortex. Anat Embryol (Berl) 1988, 179:173-179.

69. Payne JM, Hyman SL, Shores EA, North KN: Assessment of executive function and attention in children with neurofibromatosis type 1 relationships between cognitive measures and real-world behavior. Child Neuropsychol 2011, 17:313-329.

70. du Boisqueheneuc F, Levy R, Volle E, Seassau M, Duffau H, Kinkingnehun S, Samson $Y$, Zhang S, Dubois B: Functions of the left superior frontal gyrus in humans: a lesion study. Brain 2006, 129:3315-3328.

71. Tsujimoto S, Genovesio A, Wise SP: Frontal pole cortex: encoding ends at the end of the endbrain. Trends Cogn Sci 2011, 15:169-176.

72. Elliott R, Dolan RJ, Frith CD: Dissociable functions in the medial and lateral orbitofrontal cortex: evidence from human neuroimaging studies. Cereb Cortex 2000, 10:308-317

73. Zald DH, Andreotti C: Neuropsychological assessment of the orbital and ventromedial prefrontal cortex. Neuropsychologia 2010, 48:3377-3391.

74. Bush G, Luu P, Posner Ml: Cognitive and emotional influences in anterior cingulate cortex. Trends Cogn Sci 2000, 4:215-222.

75. Billingsley RL, Slopis JM, Swank PR, Jackson EF, Moore BD 3rd: Cortical morphology associated with language function in neurofibromatosis, type I. Brain Lang 2003, 85:125-139

76. Hagoort P: On Broca, brain, and binding: a new framework. Trends Cogn Sci 2005, 9:416-423.

77. Xiang HD, Fonteijn HM, Norris DG, Hagoort P: Topographical functional connectivity pattern in the perisylvian language networks. Cereb Cortex 2010, 20:549-560.
78. Cabeza R, Nyberg L: Imaging cognition II: An empirical review of 275 PET and fMRI studies. J Cogn Neurosci 2000, 12:1-47.

79. Chao LL, Haxby JV, Martin A: Attribute-based neural substrates in temporal cortex for perceiving and knowing about objects. Nat Neurosci 1999, 2:913-919

80. Gough PM, Nobre AC, Devlin JT: Dissociating linguistic processes in the left inferior frontal cortex with transcranial magnetic stimulation. J Neurosci 2005, 25:8010-8016.

81. Hartwigsen G, Baumgaertner A, Price CJ, Koehnke M, Ulmer S, Siebner HR: Phonological decisions require both the left and right supramarginal gyri. Proc Natl Acad Sci U S A 2010, 107:16494-16499.

82. Feldmann R, Denecke J, Grenzebach M, Schuierer G, Weglage J: Neurofibromatosis type 1: motor and cognitive function and T2weighted MRI hyperintensities. Neurology 2003, 61:1725-1728.

83. Rowbotham I, Pit-ten Cate IM, Sonuga-Barke EJ, Huijbregts SC: Cognitive control in adolescents with neurofibromatosis type 1. Neuropsychology 2009, 23:50-60.

84. Purves D, Williams SM: Neuroscience. 2nd edition. Sunderland, MA: Sinauer Associates; 2001

85. Clements-Stephens AM, Rimrodt SL, Gaur P, Cutting LE: Visuospatial processing in children with neurofibromatosis type 1. Neuropsychologia 2008, 46:690-697.

86. Rogers J, Kochunov P, Zilles K, Shelledy W, Lancaster J, Thompson P, Duggirala R, Blangero J, Fox PT, Glahn DC: On the genetic architecture of cortical folding and brain volume in primates. Neuroimage 2010, 53:1103-1108.

87. Rajagopalan V, Scott J, Habas PA, Kim K, Corbett-Detig J, Rousseau F, Barkovich AJ, Glenn OA, Studholme C: Local tissue growth patterns underlying normal fetal human brain gyrification quantified in utero. J Neurosci 2011, 31:2878-2887.

88. Afif A, Bouvier R, Buenerd A, Trouillas J, Mertens P: Development of the human fetal insular cortex: study of the gyration from 13 to 28 gestational weeks. Brain Struct Funct 2007, 212:335-346.

89. Caviness VS Jr: Mechanical model of brain convolutional development Science 1975, 189:18-21.

90. Kostovic I, Rakic P: Developmental history of the transient subplate zone in the visual and somatosensory cortex of the macaque monkey and human brain. I Comp Neurol 1990, 297:441-470.

91. Van Essen DC: A tension-based theory of morphogenesis and compact wiring in the central nervous system. Nature 1997, 385:313-318.

doi:10.1186/1866-1955-5-3

Cite this article as: Violante et al: Gyrification, cortical and subcortical morphometry in neurofibromatosis type 1: an uneven profile of developmental abnormalities. Journal of Neurodevelopmental Disorders 2013, 5:3.

\section{Submit your next manuscript to BioMed Central and take full advantage of:}

- Convenient online submission

- Thorough peer review

- No space constraints or color figure charges

- Immediate publication on acceptance

- Inclusion in PubMed, CAS, Scopus and Google Scholar

- Research which is freely available for redistribution 